\title{
Purpureocillium lilacinum Mediated Biosynthesis Copper Oxide Nanoparticles with Promising Removal of Dyes
}

\author{
Eman N. Hammad ${ }^{1,2}{ }^{\mathbb{D}}$, Salem S Salem ${ }^{3, *}{ }^{\mathbb{D}}$, Moustafa M. Zohair ${ }^{1}{ }^{(\mathbb{D}}$, Asem A. Mohamed ${ }^{1}{ }^{\mathbb{D}}$, Wagdi El- \\ Dougdoug 2 (i) \\ 1 Chemistry of Natural and Microbial Products Department; Pharmaceutical Industries Research Division; National \\ Research Centre; Dokki, Giza 12622, Egypt \\ 2 Department of Chemistry; Faculty of Science; Benha university; Benha 13518, Egypt \\ 3 Botany and Microbiology Department; Faculty of Science; AL-Azhar University; Nasr City; Cairo-11884, Egypt \\ * Correspondence: salemsalahsalem@azhar.edu.eg (S.S.S.);
}

Scopus Author ID 57202162965

Received: 9.05.2021; Revised: 2.06.2021; Accepted: 5.06.2021; Published: 9.06.2021

\begin{abstract}
Biosynthesized nanoparticles have a huge perspective. It is an environment-friendly, costefficient, reproducible, and energy-efficient method compared to physical or chemical synthesis. In the present study, biosynthesis of copper oxide nanoparticles (CuONP) was done using Purpureocillium lilacinum. Characterization of synthesized CuONP was done by using UV-vis spectroscopy, TEM, and XRD analysis. UV-vis gave characteristic SPR peak for CuONP at $360 \mathrm{~nm}$. TEM image reveals that the morphology of biosynthesized CuONP was spherical, and their size range between $4.03 \mathrm{~nm}$ to $8.83 \mathrm{~nm}$. The XRD analysis confirmed the crystalline nature of $\mathrm{CuO}$ with a size range of $6-26.6 \mathrm{~nm}$. Further comparative study of photocatalytic degradation of navy blue and safranin using CuONP was done. $\mathrm{CuO}-\mathrm{NPs}$ exhibited potential catalytic activity in navy blue $(57.5 \%)$ and safranin $(63 \%)$, respectively.
\end{abstract}

Keywords: Purpureocillium lilacinum; copper oxide nanoparticles; characterization; photocatalytic dye degradation.

(C) 2021 by the authors. This article is an open-access article distributed under the terms and conditions of the Creative Commons Attribution (CC BY) license (https://creativecommons.org/licenses/by/4.0/).

\section{Introduction}

Nanotechnology has become invading all fields because of its clear and distinctive effects that provide the scientific community with many developments that affect the medical, agricultural, etc. [1-8]. Nanomaterials are synthesized in different methods (physical, chemical and biological), where biological methods are a good way to synthesize nanoparticles, and nanomaterials are used in multiple applications [9-15]. Fungi are one of the most important groups of microbes, as they are used in many applications such as bio-processing, removal of bio-inks, enzyme production, food products, and nanotechnology [16-19]. Biologically synthesized metal nanoparticles are stable and biosafety and also eco-friendly [4,20-23]. The copper NPs are extremely interactive due to their high surface-to-volume rate, raising their antimicrobial and antioxidant properties [3,24,25]. Copper oxide (CuONP) has engaged numerous researchers' attention for its chemical and biological demeanor, which can be returned to its morphology [26-28]. CuO-NPs have been utilized in multiple diverse applications [18,29-31]. Therefore, this study aimed to myco-synthesize copper oxide nanoparticles, characterization by UV-vis spectroscopy, TEM, and XRD analysis, and it used photocatalytic degradation of navy blue and safranin in vitro. 


\section{Materials and Methods}

\subsection{Collection of samples.}

Fresh soil sample from rhizosphere area of three plants wheat (Triticum aestivum), Zea mays, and Medicago sativa, cultivated on the experimental farm for field corps, Faculty of Agriculture, Cairo University. Soil samples were taken from approximately $10 \mathrm{~cm}$ depth. All of these samples undergo screening for fungal isolates.

\subsection{Fungal isolation and purification and identification.}

One gram (1 g) of each soil sample was suspended in $100 \mathrm{ml}$ distilled water. One milliliter $(1 \mathrm{ml})$ from $10^{-1}-10^{-6}$ dilutions of soil suspension plated on Czapek-Dox media containing roxil 500 to suppress bacterial growth [32]. After one week of incubation at $28^{\circ} \mathrm{C}$, when mycelium tips were observable, each hyphal tip was transferred onto a fresh PDA slant. For the purification of fungal strains, this step was deemed uniform. All pure isolates were numbered and stored on the surface of PDA slant at $4{ }^{\circ} \mathrm{C}$ for further study. Most fungal isolate inoculated in $250 \mathrm{ml}$ flasks containing $100 \mathrm{ml}$ potato dextrose broth media (fermentative medium) and adjusted the initial $\mathrm{pH}$ at 7 then incubated for 6 days for copper oxide nanoparticles production at $28{ }^{\circ} \mathrm{C}$ static conditions.

\subsection{Identification of the most potent fungal isolate.}

Identification of the selected most potent fungal isolate which has high potency to produce CuONPs. Fungal isolate was subjected to cultural and morphological characterization, as well molecular identification was conducted based on amplification and sequencing of internal transcribed spacer (ITS) region.

\subsection{Preparation of CuONPs using biomass filtrates.}

In this study, $\mathrm{CuSO}_{4} .5 \mathrm{H}_{2} \mathrm{O}$ is used as a precursor to producing CuONP. The biomass filtrate that was collected is used to prepare the $\mathrm{CuONP}$ as follows: The filtrate's $\mathrm{pH}$ is adjusted at $\mathrm{pH} 9$, and $1 \mathrm{mM} \mathrm{CuSO}_{4} .5 \mathrm{H}_{2} \mathrm{O}$ were used for $\mathrm{NP}$ synthesis and incubated at $28{ }^{\circ} \mathrm{C}$ for $24 \mathrm{~h}$ in the dark.

\subsection{Characterization.}

The qualitative biosynthesis of CuONPs was examined by a color change and UVvisible spectroscopy. CuONPs synthesis is indicated by a change in color from colorless to bluish green after the addition of biomass filtrate. Further confirmation of synthesized CuONP was done by UV-vis s spectrophotometer (PerkinElmer UV/VIS Lambda 365). The biomass filtrate was taken as blank. CuONPs were characterized at a wavelength range of 300-700 nm. TEM was used for the shape analysis of synthesized nanoparticles and size confirmation. Xray diffraction patterns were obtained with the XRD 6000 series, including stress analysis, residual-austenite quantitation, crystallite size/lattice, crystallite calculation, and materials analysis by overlaid X-ray diffraction-patterns Shimadzu-apparatus using a filter of nickel and target of Cu-Ka, Shimadzu-Scientific Instruments (SSI), Kyoto Japan. The average crystallite size of CuONPs can also be measured utilizing the Debye-scherrer equation:

$\mathrm{D}=\mathrm{k} \lambda / \beta \operatorname{Cos} \theta$. 
- D is the average crystallite size (nm).

- $\mathrm{k}$ is the Scherrer constant with a value from 0.9 to 1 .

$-\lambda$ is the $\mathrm{X}$-ray wavelength.

- $\beta$ is the full width of half maximum.

- $\theta$ is the Bragg diffraction angle (degrees).

\subsection{Application of $\mathrm{CuONP}$ in dyes decolorization processes.}

Efficacy of the CuONP for dye degradation was assessed as following $10 \mathrm{ml}$ of 100 ppm Navy blue dye and safranin was added to $1 \mathrm{ml}$ of CuONP synthesized from $1 \mathrm{mM}$ of $\mathrm{CuSO}_{4} .5 \mathrm{H}_{2} \mathrm{O}$ in the presence of light. The solution was kept for stirring in light for $0-2 \mathrm{~h}$ to check the degradation rate. The dye degradation process was analyzed by UV-vis spectrophotometer. Solution of dye+water was taken as blank. Different time intervals $(0.5,1.0$, $1.5,2 \mathrm{~h}$ ) was taken to measure color removal due to CuONP treatment as follows: $1 \mathrm{~mL}$ of each treatment mixture was withdrawn and centrifuged at $4000 \mathrm{rpm}$ for five minutes, and optical density (O.D.) was measured using a spectrophotometer Experiments were repeated thrice and mean percentage value was recorded.

Percentage $(\%)$ of color removal was measured using the following formula:

$$
\mathrm{D}(\%)=(\text { Dye }(\mathrm{i})-\mathrm{Dye}(\mathrm{I})) / \text { Dye }(\mathrm{i}) * 100
$$

where D (\%) is the decolorization percentage; Dye (i) is the initial absorbance; and Dye (I) is the final absorbance.

\subsection{Statistical analysis.}

Means of three replicates and standard errors were calculated for all obtained results, and the data were subjected to analysis of variance means using sigma plot 12.5 programs.

\section{Results and Discussion}

\subsection{Identification of the most potent fungal isolate.}

According to the cultural and morphological characteristics and phylogenetic analysis of isolate, the 18S rRNA gene analysis of the fungal isolate Eman2021 showed similarity with Purpureocillium lilacinum, as shown in a phylogenetic tree Figure 1. The Gen Bank accession number for strain Eman2021 nucleotide sequence is MW831030.1, identified as Purpureocillium lilacinum Eman2021.

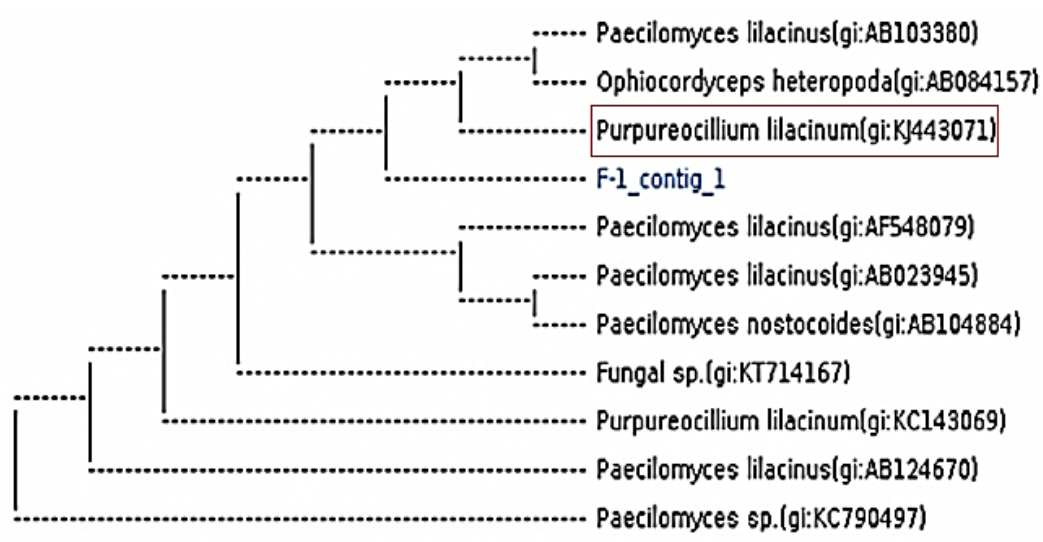

Figure 1. Phylogenetic analysis of ITS sequences of the fungal strain with the sequences from NCBI. Symbol F1_contig_1refers to ITS fragments retrieved from this study. 


\subsection{Characterization.}

CuONPs were synthesized using $1 \mathrm{mM} \mathrm{CuSO}$. The immediate color change was observed to bluish-green, which indicates the formation of CuONP [33]. The absorbance peak of CuONP was in the range of 250-360 nm. Maximum SPR peak for CuONP was observed at $360 \mathrm{~nm}$ Figure 2. Another report showed that the maximum absorption peak of CuONPs at $335 \mathrm{~nm}$ [34].

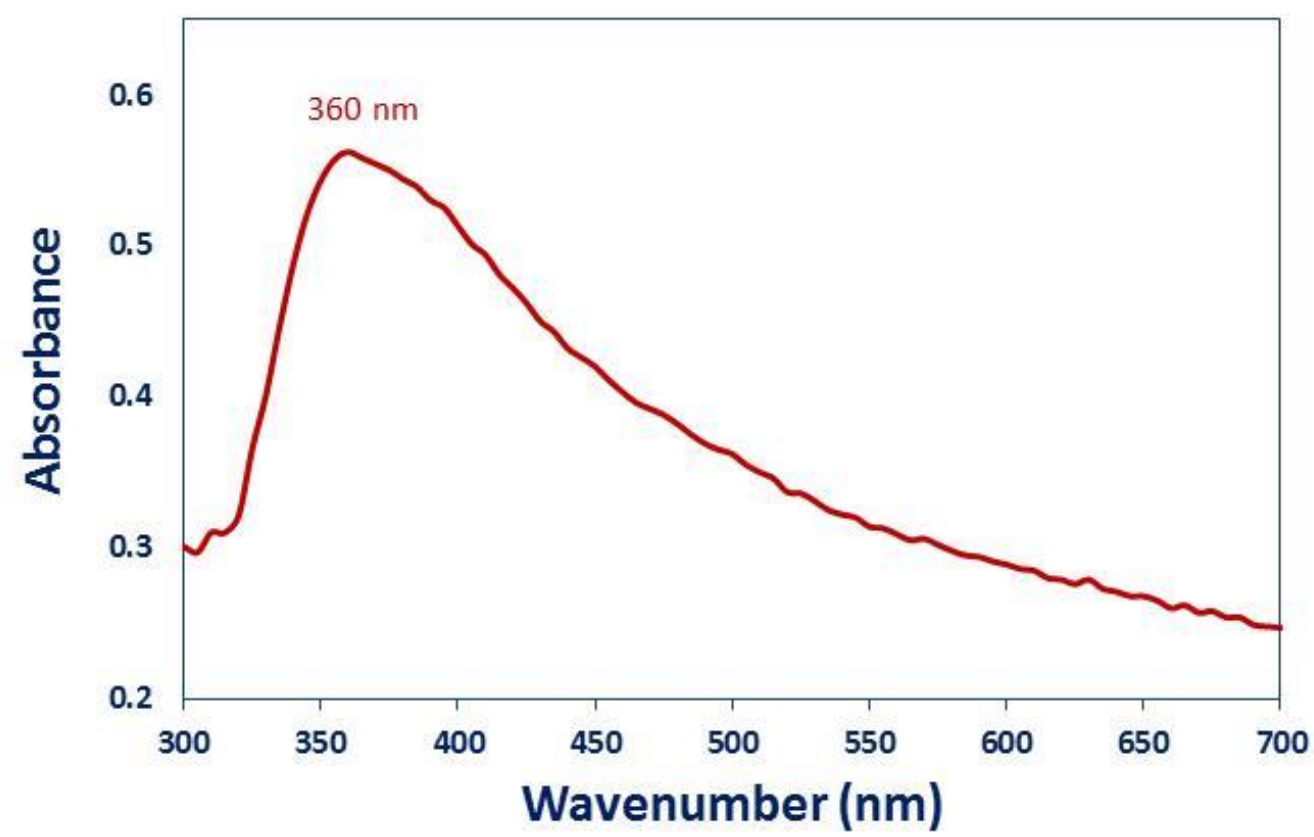

Figure 2. UV-visible spectra of CuONPs synthesized by Purpureocillium lilacinum.

CuO-NPs have been characterized by TEM (JEOL-2100) to determine the size and shape of nanoparticles. TEM image reveals that the morphology of biosynthesized CuONP was spherical and their size range between $4.03 \mathrm{~nm}$ to $8.83 \mathrm{~nm}$ Figure 3. Figure 3 shows the areaselected electron diffraction (SAED) patterns of the CuONPs, indicating good sharp rings, which reveal the poly-crystallized nature of the CuONPs. In a previous study, it was shown that the size of copper oxide ranges between 78-80nm [35], where these sizes have a role in the color removal process and show the effect of copper oxide on the dyes.

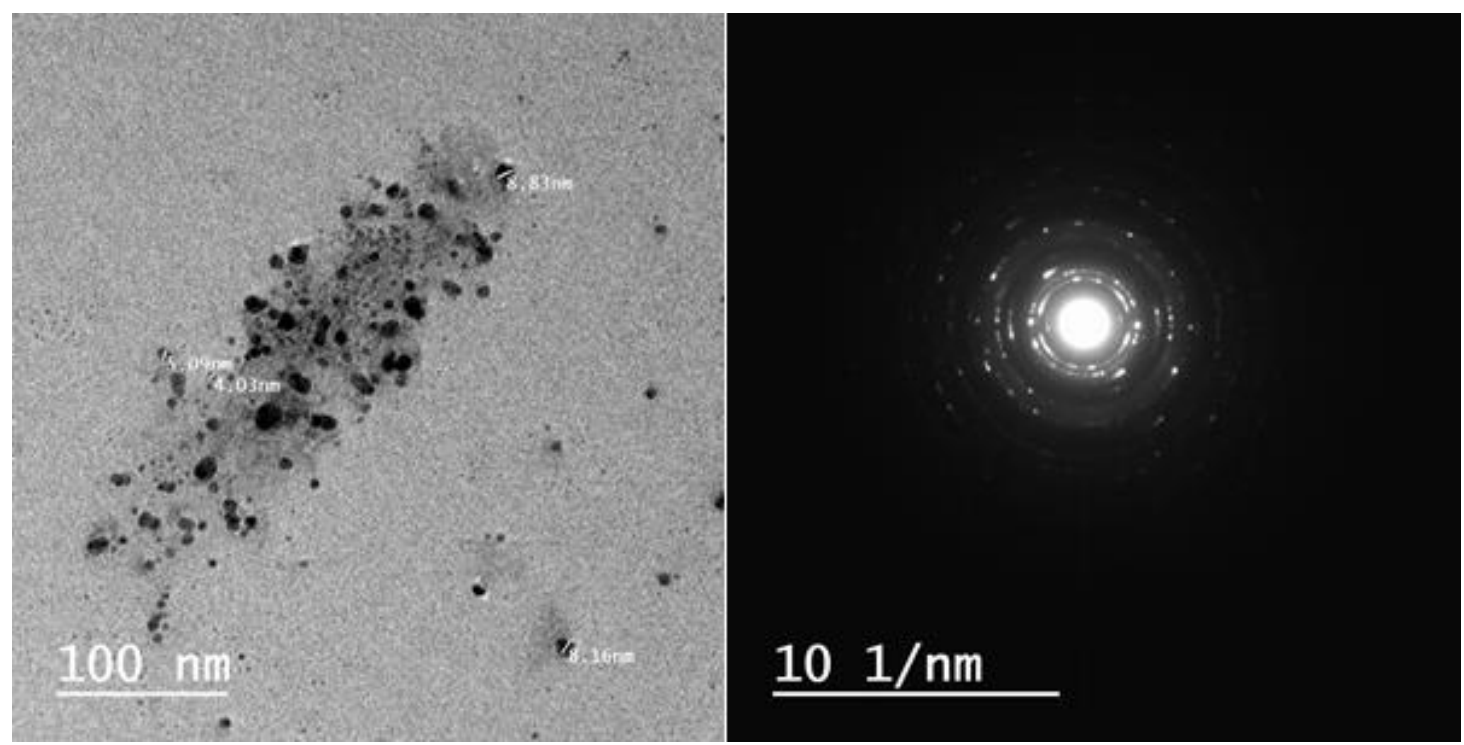

Figure 3. TEM image with SAED pattern of CuONPs synthesized by Purpureocillium lilacinum. 
Further studies were carried out using X-ray diffraction to confirm the crystalline nature of the particle. As seen in Figure 4, XRD based CuO-NPs characterization exhibit nine peaks at $2 \theta$ values $35.5^{\circ}, 38.7^{\circ}, 48.8^{\circ}, 54^{\circ}, 61.5^{\circ}$, and $66.3^{\circ}$ which assigned to planes 002,111 , 202, 020, -113 , and -311 respectively for $\mathrm{CuO}-\mathrm{NPs}$. The visualized XRD peaks are matched with JCPDS number: 00-041-0254 of crystallographic CuONPs [36]. In line with our clarification of the results, [27,37,38] reported that the successful fabrication of crystallite, monoclinic phase CuONPs at the same XRD diffraction planes utilizing metabolites of fungal. The average sizes of crystallite $\mathrm{CuO}$ - particles were calculated using Scherrer's equation. In this context, the size of $\mathrm{CuO}$ - particles ranged between 6-26.6nm, output from the analysis of the equation.

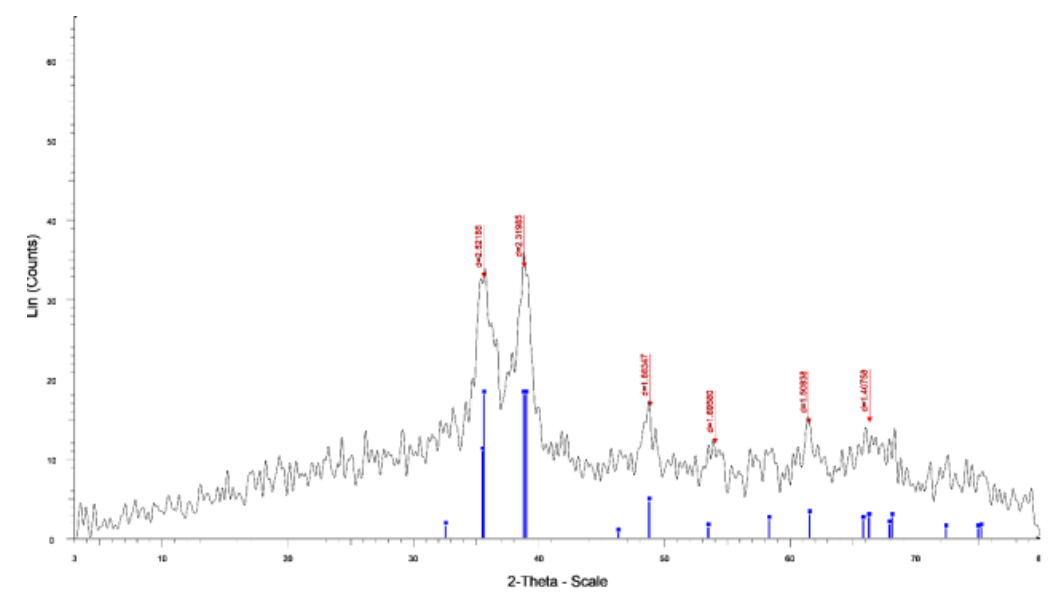

Figure 4. XRD pattern of CuONP synthesized by Purpureocillium lilacinum.

\subsection{Navy blue and safranin removal by CuONP.}

The CuONPs from Purpureocillium lilacinum was applied to de-colorize two dyes; navy blue and safranin, at 100ppm. The decolorization percentage of two dyes was increased by increasing gradually in time and appeared its high effect after 120min Figure 5. The results showed that decolorization percentages of the navy blue and safranin dyes by CuONPs were 57.5 and $63 \%$, respectively, after incubation, as shown in Figure 5. In a previous study, the effect of copper oxide nanoparticles was evaluated on a wide range of synthetic dyes as Methyl Orange (MO), Safranin O, Coomassie Brilliant Blue R-250 (CBB), Methylene Blue (MB), and Congo Red (CR) [39]. Other reports use $\mathrm{CuO}$ to remove $\mathrm{MB}$ and $\mathrm{CR}$ dyes [28,40].

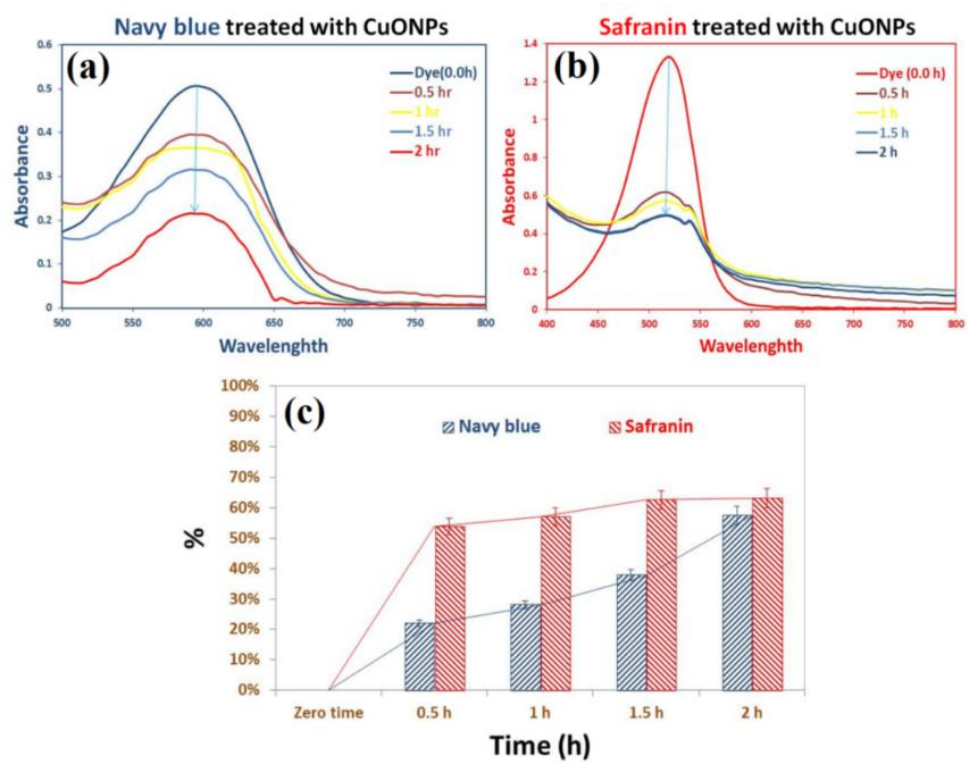

Figure 5. (a) Navy blue and (b) safranin treated with CuONPs with (c) removal percentage. 


\section{Conclusions}

In the current study, Purpureocillium lilacinum was exploited in the biogenesis of nano $\mathrm{CuO}$. Extracellular enzymes were functionalized in the biogenesis and capping processes of nano-metal formation. Characterizations of CuONPs produced under optimal conditions were performed. CuO-NPs exhibited potential catalytic activity in navy blue (57.5\%) and safranin (63\%), respectively. Where copper oxide is used to remove dye pollutants from the environment and helps reduce environmental pollutants.

\section{Funding}

This research received no external funding.

\section{Acknowledgments}

The authors express their sincere thanks to the National Research Centre of Egypt, for providing the necessary research facilities.

\section{Conflicts of Interest}

The authors declare no conflict of interest.

\section{References}

1. Joshi, N.; Pathak, A.; Anupam, R.; Jain, N.; Singh, J.; Upadhyaya, C.P. A Rapid and Efficient Biosynthesis of Metallic Nanoparticles Using Aqueous Extract of Chia (Salvia hispanica L.) Seeds. BioNanoScience 2019, 9 , 893-902, doi:10.1007/s12668-019-00672-6.

2. Arvindganth, R.; Kathiravan, G. Biogenic Synthesis of Gold Nanoparticle from Enicostema axillare and Their In Vitro Cytotoxicity Study Against MCF-7 Cell Line. BioNanoScience 2019, 9, 839-847, doi:10.1007/s12668-019-00656-6.

3. Salem, S.S.; Fouda, A. Green Synthesis of Metallic Nanoparticles and Their Prospective Biotechnological Applications: an Overview. Biological Trace Element Research 2021, 199, 344-370, doi:10.1007/s12011-02002138-3.

4. Karunakaran, G.; Jagathambal, M.; Gusev, A.; Torres, J.A.L.; Kolesnikov, E.; Kuznetsov, D. Rapid Biosynthesis of AgNPs Using Soil Bacterium Azotobacter vinelandii With Promising Antioxidant and Antibacterial Activities for Biomedical Applications. JOM 2017, 69, 1206-1212, doi:10.1007/s11837-0162175-8.

5. Aref, M.S.; Salem, S.S. Bio-callus synthesis of silver nanoparticles, characterization, and antibacterial activities via Cinnamomum camphora callus culture. Biocatalysis and Agricultural Biotechnology 2020, 27, doi:10.1016/j.bcab.2020.101689.

6. Salem, S.S.; El-Belely, E.F.; Niedbała, G.; Alnoman, M.M.; Hassan, S.E.D.; Eid, A.M.; Shaheen, T.I.; Elkelish, A.; Fouda, A. Bactericidal and in-vitro cytotoxic efficacy of silver nanoparticles (Ag-NPs) fabricated by endophytic actinomycetes and their use as coating for the textile fabrics. Nanomaterials 2020, 10, 1-20, doi:10.3390/nano10102082.

7. Abu-Elghait, M.; Hasanin, M.; Hashem, A.H.; Salem, S.S. Ecofriendly novel synthesis of tertiary composite based on cellulose and myco-synthesized selenium nanoparticles: Characterization, antibiofilm and biocompatibility. International Journal of Biological Macromolecules 2021, 175, 294-303, doi:10.1016/j.ijbiomac.2021.02.040.

8. Shaheen, T.I.; Salem, S.S.; Zaghloul, S. A New Facile Strategy for Multifunctional Textiles Development through in Situ Deposition of SiO2/TiO2 Nanosols Hybrid. Industrial and Engineering Chemistry Research 2019, 58, 20203-20212, doi:10.1021/acs.iecr.9b04655.

9. Salem, S.S.; Fouda, M.M.G.; Fouda, A.; Awad, M.A.; Al-Olayan, E.M.; Allam, A.A.; Shaheen, T.I. Antibacterial, Cytotoxicity and Larvicidal Activity of Green Synthesized Selenium Nanoparticles Using Penicillium corylophilum. Journal of Cluster Science 2021, 32, 351-361, doi:10.1007/s10876-020-01794-8. 
10. Elfeky, A.S.; Salem, S.S.; Elzaref, A.S.; Owda, M.E.; Eladawy, H.A.; Saeed, A.M.; Awad, M.A.; AbouZeid, R.E.; Fouda, A. Multifunctional cellulose nanocrystal /metal oxide hybrid, photo-degradation, antibacterial and larvicidal activities. Carbohydrate Polymers 2020, 230, 115711, doi:https://doi.org/10.1016/j.carbpol.2019.115711.

11. Abdelmoneim, H.E.M.; Wassel, M.A.; Elfeky, A.S.; Bendary, S.H.; Awad, M.A.; Salem, S.S.; Mahmoud, S.A. Multiple Applications of CdS/TiO2 Nanocomposites Synthesized via Microwave-Assisted Sol-Gel. Journal of Cluster Science 2021, 10.1007/s10876-021-02041-4, doi:10.1007/s10876-021-02041-4.

12. Alsharif, S.M.; Salem, S.S.; Abdel-Rahman, M.A.; Fouda, A.; Eid, A.M.; El-Din Hassan, S.; Awad, M.A.; Mohamed, A.A. Multifunctional properties of spherical silver nanoparticles fabricated by different microbial taxa. Heliyon 2020, 6, doi:10.1016/j.heliyon.2020.e03943.

13. Eid, A.M.; Fouda, A.; Niedbała, G.; Hassan, S.E.D.; Salem, S.S.; Abdo, A.M.; Hetta, H.F.; Shaheen, T.I. Endophytic streptomyces laurentii mediated green synthesis of Ag-NPs with antibacterial and anticancer properties for developing functional textile fabric properties. Antibiotics 2020, 9, 1-18, doi:10.3390/antibiotics9100641.

14. Mohamed, A.A.; Fouda, A.; Abdel-Rahman, M.A.; Hassan, S.E.D.; El-Gamal, M.S.; Salem, S.S.; Shaheen, T.I. Fungal strain impacts the shape, bioactivity and multifunctional properties of green synthesized zinc oxide nanoparticles. Biocatalysis and Agricultural Biotechnology 2019, 19, doi:10.1016/j.bcab.2019.101103.

15. Sharaf, O.M.; Al-Gamal, M.S.; Ibrahim, G.A.; Dabiza, N.M.; Salem, S.S.; El-ssayad, M.F.; Youssef, A.M. Evaluation and characterization of some protective culture metabolites in free and nano-chitosan-loaded forms against common contaminants of Egyptian cheese. Carbohydrate Polymers 2019, 223, 115094, doi:https://doi.org/10.1016/j.carbpol.2019.115094.

16. Copetti, M.V. Fungi as industrial producers of food ingredients. Current Opinion in Food Science 2019, 25 , 52-56, doi:https://doi.org/10.1016/j.cofs.2019.02.006.

17. Selim, M.T.; Salem, S.S.; Mohamed, A.A.; El-Gamal, M.S.; Awad, M.F.; Fouda, A. Biological treatment of real textile effluent using aspergillus flavus and fusarium oxysporium and their consortium along with the evaluation of their phytotoxicity. Journal of Fungi 2021, 7, doi:10.3390/jof7030193.

18. Shaheen, T.I.; Salem, S.S.; Fouda, A. Current Advances in Fungal Nanobiotechnology: Mycofabrication and Applications. In Microbial Nanobiotechnology: Principles and Applications, Lateef, A., Gueguim-Kana, E.B., Dasgupta, N., Ranjan, S., Eds. Springer Singapore: Singapore, 2021; 10.1007/978-981-33-47779_4pp. 113-143.

19. Hashem, A.H.; Khalil, A.M.A.; Reyad, A.M.; Salem, S.S. Biomedical Applications of Mycosynthesized Selenium Nanoparticles Using Penicillium expansum ATTC 36200. Biological Trace Element Research 2021, 10.1007/s12011-020-02506-z, doi:10.1007/s12011-020-02506-z.

20. Kaur, M. Impact of Response Surface Methodology-Optimized Synthesis Parameters on In vitro Antiinflammatory Activity of Iron Nanoparticles Synthesized using Ocimum tenuiflorum Linn. BioNanoScience 2020, 10, 1-10, doi:10.1007/s12668-019-00681-5.

21. Nazari, F.; Movafeghi, A.; Jafarirad, S.; Kosari-Nasab, M.; Divband, B. Synthesis of Reduced Graphene Oxide-Silver Nanocomposites and Assessing Their Toxicity on the Green Microalga Chlorella vulgaris. BioNanoScience 2018, 8, 997-1007, doi:10.1007/s12668-018-0561-0.

22. Karunakaran, G.; Jagathambal, M.; Van Minh, N.; Kolesnikov, E.; Kuznetsov, D. Green Synthesis of NiFe2O4 Spinel-Structured Nanoparticles Using Hydrangea paniculata Flower Extract with Excellent Magnetic Property. JOM 2018, 70, 1337-1343, doi:10.1007/s11837-018-2871-7.

23. Mishra, A.N.; Bhadauria, S.; Gaur, M.S.; Pasricha, R. Extracellular microbial synthesis of gold nanoparticles using fungus Hormoconis resinae. JOM 2010, 62, 45-48, doi:10.1007/s11837-010-0168-6.

24. Datta Majumdar, T.; Ghosh, C.K.; Mukherjee, A. Dual Role of Copper Nanoparticles in Bacterial Leaf Blight-Infected Rice: A Therapeutic and Metabolic Approach. ACS Agricultural Science \& Technology 2021, 10.1021/acsagscitech.0c00064, doi:10.1021/acsagscitech.0c00064.

25. Karpov, I.V.; Ushakov, A.V.; Demin, V.G.; Goncharova, E.A.; Shaihadinov, A.A. Investigation of the Quenching Rate Effect on the Ferromagnetic Properties of CuO Nanoparticles. JOM 2020, 72, 3952-3957, doi:10.1007/s11837-020-04221-5.

26. Karuppannan, S.K.; Ramalingam, R.; Mohamed Khalith, S.B.; Dowlath, M.J.H.; Darul Raiyaan, G.I.; Arunachalam, K.D. Characterization, antibacterial and photocatalytic evaluation of green synthesized copper oxide nanoparticles. Biocatalysis and Agricultural Biotechnology 2021, 31, 101904, doi:https://doi.org/10.1016/j.bcab.2020.101904. 
27. Shaheen, T.I.; Fouda, A.; Salem, S.S. Integration of Cotton Fabrics with Biosynthesized CuO Nanoparticles for Bactericidal Activity in the Terms of Their Cytotoxicity Assessment. Industrial and Engineering Chemistry Research 2021, 60, 1553-1563, doi:10.1021/acs.iecr.0c04880.

28. Sinha, T.; Ahmaruzzaman, M. Green synthesis of copper nanoparticles for the efficient removal (degradation) of dye from aqueous phase. Environmental Science and Pollution Research 2015, 22, 20092 20100, doi:10.1007/s11356-015-5223-y

29. Jamdade, D.A.; Rajpali, D.; Joshi, K.A.; Kitture, R.; Kulkarni, A.S.; Shinde, V.S.; Bellare, J.; Babiya, K.R.; Ghosh, S. Gnidia glauca-and Plumbago zeylanica-mediated synthesis of novel copper nanoparticles as promising antidiabetic agents. Advances in pharmacological sciences 2019, 2019, doi:https://doi.org/10.1155/2019/9080279.

30. Dulta, K.; Ağçeli, G.K.; Chauhan, P.; Chauhan, P.K. Biogenic Production and Characterization of CuO Nanoparticles by Carica papaya Leaves and Its Biocompatibility Applications. Journal of Inorganic and Organometallic Polymers and Materials 2021, 31, 1846-1857, doi:10.1007/s10904-020-01837-7.

31. Fouda, A.; Salem, S.S.; Wassel, A.R.; Hamza, M.F.; Shaheen, T.I. Optimization of green biosynthesized visible light active $\mathrm{CuO} / \mathrm{ZnO}$ nano-photocatalysts for the degradation of organic methylene blue dye. Heliyon 2020, 6, doi:10.1016/j.heliyon.2020.e04896.

32. Salem, S.S.; Mohamed, A.A.; Gl-Gamal, M.S.; Talat, M.; Fouda, A. Biological decolorization and degradation of azo dyes from textile wastewater effluent by Aspergillus niger. Egyptian Journal of Chemistry 2019, 62, 1799-1813, doi:10.21608/EJCHEM.2019.11720.1747.

33. Hassan, S.E.-D.; Salem, S.S.; Fouda, A.; Awad, M.A.; El-Gamal, M.S.; Abdo, A.M. New approach for antimicrobial activity and bio-control of various pathogens by biosynthesized copper nanoparticles using endophytic actinomycetes. Journal of Radiation Research and Applied Sciences 2018, 11, 262-270, doi:10.1016/j.jrras.2018.05.003.

34. Mohamed, A.A.; Abu-Elghait, M.; Ahmed, N.E.; Salem, S.S. Eco-friendly Mycogenic Synthesis of ZnO and $\mathrm{CuO}$ Nanoparticles for In Vitro Antibacterial, Antibiofilm, and Antifungal Applications. Biological Trace Element Research 2020, 10.1007/s12011-020-02369-4, doi:10.1007/s12011-020-02369-4.

35. Hassan, S.E.D.; Fouda, A.; Radwan, A.A.; Salem, S.S.; Barghoth, M.G.; Awad, M.A.; Abdo, A.M.; ElGamal, M.S. Endophytic actinomycetes Streptomyces spp mediated biosynthesis of copper oxide nanoparticles as a promising tool for biotechnological applications. Journal of Biological Inorganic Chemistry 2019, 10.1007/s00775-019-01654-5, doi:10.1007/s00775-019-01654-5.

36. Nayak, R.; Ali, F.A.; Mishra, D.K.; Ray, D.; Aswal, V.K.; Sahoo, S.K.; Nanda, B. Fabrication of CuO nanoparticle: An efficient catalyst utilized for sensing and degradation of phenol. Journal of Materials Research and Technology 2020, 9, 11045-11059, doi:https://doi.org/10.1016/j.jmrt.2020.07.100.

37. Badawy, A.A.; Abdelfattah, N.A.H.; Salem, S.S.; Awad, M.F.; Fouda, A. Efficacy assessment of biosynthesized copper oxide nanoparticles (Cuo-nps) on stored grain insects and their impacts on morphological and physiological traits of wheat (triticum aestivum 1.) plant. Biology 2021, 10, doi:10.3390/biology10030233.

38. Karunakaran, G.; Jagathambal, M.; Kumar, G.S.; Kolesnikov, E. Hylotelephium telephium Flower ExtractMediated Biosynthesis of $\mathrm{CuO}$ and $\mathrm{ZnO}$ Nanoparticles with Promising Antioxidant and Antibacterial Properties for Healthcare Applications. JOM 2020, 72, 1264-1272, doi:10.1007/s11837-020-04007-9.

39. Venkata, A.L.K.; Anthony, S.P.; Muthuraman, M.S. Synthesis of Solanum nigrum mediated copper oxide nanoparticles and their photocatalytic dye degradation studies. Materials Research Express 2019, 6, 125402, doi:10.1088/2053-1591/ab52a6.

40. Sathiyavimal, S.; Vasantharaj, S.; Veeramani, V.; Saravanan, M.; Rajalakshmi, G.; Kaliannan, T.; AlMisned, F.A.; Pugazhendhi, A. Green chemistry route of biosynthesized copper oxide nanoparticles using Psidium guajava leaf extract and their antibacterial activity and effective removal of industrial dyes. Journal of Environmental Chemical Engineering 2021, 9, 105033, doi:https://doi.org/10.1016/j.jece.2021.105033. 